\title{
A PREPARAÇÃO DE CRIANÇAS E ADOLESCENTES PARA A ADOÇÃO: O LUGAR DO ESTUDANTE DE PSICOLOGIA
}

\author{
Isabel Cristina Gomes \\ Universidade de São Paulo
}

\author{
Lidia Levy \\ Pontifícia Universidade Católica do Rio de Janeiro
}

\begin{abstract}
Resumo
Esse artigo tem como objetivo refletir acerca da participação do estudante de Psicologia, incluído em programa de estágio supervisionado, na preparação de crianças, adolescentes e grupo de irmãos para a inserção em família adotiva. Numa revisão de literatura, propostas interventivas voltadas à preparação tanto no âmbito da adoção nacional quanto da internacional são apresentadas. Por meio de vinhetas clínicas e de um enfoque psicanalítico, discutimos a importância de um diálogo interdisciplinar entre a academia, o judiciário e as instituições de acolhimento voltados para a consolidação dos vínculos entre crianças/adolescentes e os adotantes. Abordamos, ainda, o lugar do terapeuta/estagiário e os limites de sua atuação, constituindo-se em experiência rica para seu desenvolvimento pessoal e profissional, bem como para a construção de conhecimento para a área.
\end{abstract}

Palavras-chave: formação profissional do psicólogo; adoção, psicanálise.

\section{THE PREPARATION OF CHILDREN AND ADOLESCENTS FOR ADOPTION: THE PSYCHOLOGY STUDENT'S PLACE}

\begin{abstract}
This article aims to reflect on the participation of the psychology student included in a supervised internship program, in the preparation of children, adolescents and group of siblings for insertion into an adoptive family. It is presented some intervention proposals aimed at preparing both in the scope of national and international adoption based on the review of the literature. Through clinical reports and a psychoanalytic approach, it is discussed the importance of an interdisciplinary dialogue between the academy, the judiciary and the home institutions aimed at consolidating the bonds between children or adolescents and adopters. We also emphasize the therapist trainee's (student) place and the limits of his/her performance constituting a valuable experience for his/her personal and professional development, as well as the construction of knowledge for the area.
\end{abstract}

Keywords: psychologist's professional training; adoption; psychoanalysis.

\section{LA PREPARACIÓN DE NIÑOS Y ADOLESCENTES EN LA ADOPCIÓN: EL LUGAR DEL ESTUDIANTE DE PSICOLOGIA}

\begin{abstract}
Resumen
Este artículo pretende reflexionar sobre la participación del estudiante de psicología incluida en el programa de prácticas supervisadas en la preparación de los niños, adolescentes y grupo de hermanos para su inserción en familia sustituta. En una revisión de la literatura se presentan propuestas de intervención dirigidas a preparar a la adopción nacional e internacional. A través de viñetas clínicas y de un enfoque psicoanalítico discutimos la importancia de un diálogo interdisciplinario entre la academia, el poder judicial y las instituciones de acogida destinadas a la consolidación de los vínculos entre niños y adolescentes y adoptantes. Se discute el lugar del terapeuta/aprendiz y los límites de su actuar, siendo rica experiencia para su desarrollo personal y profesional, así como para la construcción del conocimiento en el área.
\end{abstract}

Palabras clave: formación professional del psicologo; adopción; psicoanálisis. 


\section{BREVE INTRODUÇÃO}

A recomendação legal de que crianças e adolescentes acolhidos institucionalmente sejam preparados por equipe interprofissional, antes da inclusão em família adotiva, incitou os profissionais a se preparem e a elaborarem novos procedimentos. As equipes técnicas das Varas da Infância e da Juventude e os profissionais das instituições de acolhimento reconhecem a importância de desenvolverem um trabalho conjunto, mas também percebem algumas dificuldades em sua execução. Para dar conta da tarefa, algumas Varas buscam realizar parcerias com os serviços-escolas de algumas universidades, seja para a avaliação dos pretendentes para inclusão no cadastro nacional de adoção quanto para a realização dos grupos reflexivos com essa mesma população. Nesse artigo nos deteremos em outra vertente da parceria, o atendimento de crianças/adolescentes que passaram por experiências fracassadas em tentativas de adoção e, possivelmente, serão indicadas para uma nova família.

No campo das ciências humanas e da saúde é comum parcerias ou convênios entre determinados órgãos públicos, ONGs e as universidades, em que ambas se beneficiam, já que os primeiros recebem uma oferta de serviços profissionais específicos e a academia ganha um campo para formação e pesquisa. É nessa dimensão que discutiremos a "preparação de quem prepara", abordando nossa experiência em supervisionar graduandos envolvidos com atividades de preparação de pretendentes à adoção e de crianças/adolescentes para serem colocados em nova família.

No geral, os cursos de Psicologia se pautam pela oferta inicial de conhecimentos teóricos básicos, abrangendo múltiplas áreas de conhecimento, pesquisa e atuação do psicólogo. Entretanto, é na esfera da atuação profissional que o aluno vai incorporando uma nova identidade, ou seja, a passagem de estudante para profissional. Segundo Zuanazzi e Gomes (2018), o "ser aluno" é algo que acompanha os jovens universitários desde sempre, ou seja, alguns entram na pré-escola muito cedo e essa identidade introjetada precocemente estabelece os parâmetros e finalidades desse estado ou função.

Cabe ao aluno estudar, aprender, e ao professor ensinar. A chegada à universidade abre um campo novo, pois se espera maior autonomia do primeiro, em função de um interesse genuíno frente ao campo escolhido a ser desvendado, pesquisado e dominado. O aluno, por sua vez, também coloca expectativas sobre a figura do professor que serão ou não realizadas. Aulas expositivas, seminários, presenciais ou à distância, fazem o rol dos instrumentos a serem utilizados no ensinar. Entretanto, a natureza desse ensinar se particulariza quando nos colocamos frente à formação profissional. Neste texto, destacamos a singularidade da formação clínica e da relação supervisor/estagiário, sob o referencial psicanalítico. Hoje ainda nos amparamos no que Freud propôs em 
1913 sobre as "recomendações aos médicos" que iriam exercer a psicanálise como prática terapêutica: a importância do tripé: teoria, análise pessoal e a supervisão com alguém mais experiente.

Tradicionalmente, o principal campo de prática clínica do estudante são os serviços-escolas, com suas clínicas psicológicas, nas quais os estagiários, via de regra, iniciam os atendimentos a pacientes e/ou famílias, começam a construir a identidade de psicoterapeutas, aqui ancorados nos referenciais psicanalíticos, amparados pelos aparatos da instituição acadêmica da qual fazem parte. É rica a literatura produzida sobre a formação da atitude clínica do futuro terapeuta (Aguirre et al., 2000) e diversos estudos sempre consideraram que o desenvolvimento e refinamento do olhar e ouvir clínico se dá por meio de aprendizagem teórica e/ou supervisões de casos atendidos (Sandler, Dare, \& Holder, 1977; Meira \& Nunes, 2005; Gomes, 2005; De Fillippo, 2008; Marcos, 2011).

São mais recentes os estudos que discutem a formação do estudante para o atendimento a famílias, considerando-se suas especificidades, quando comparado ao de pacientes individuais; bem como, ao cuidado que é requerido frente aos graduandos de Psicologia que o iniciam, para que conteúdos ligados à própria herança familiar não venham comprometer o atendimento clínico a ser oferecido (Zanetti \& Gomes, 2016; Zuanazzi, 2015; Sei \& Gomes, 2017). Contudo, a manutenção do tripé proposto por Freud, há mais de um século, continua imperando na medida em que se exige do estagiário que ele tenha uma determinada bagagem teórica, que passe ou tenha passado por algum processo psicoterápico e que seja acompanhado por um supervisor/docente.

A relação supervisor/estagiário ganha nuances mais sensíveis quando comparada com a relação docente/aluno, já que se encontra em jogo outra instância, o paciente, que vem em busca de ajuda para um sofrimento psíquico individual ou vincular. Os atores envolvidos na preparação de crianças/adolescentes para uma adoção, principalmente quando estas já passaram por uma experiência de devolução, são tocados por esta experiência.

Não apenas o estagiário/terapeuta, mas também os profissionais da instituição de acolhimento e os técnicos das Varas de Infância e Juventude, se dão conta da relevância do trabalho conjunto. A interdisciplinaridade, o trabalho integrado entre as equipes e as informações compartilhadas são fundamentais para o melhor resultado possível no processo de adoção. Alguns questionamentos e propostas de procedimentos começam a ganhar lugar na literatura sobre o tema e serão aqui apresentadas. Por meio de vinhetas clínicas representativas de vários casos atendidos, discutiremos a importância e as dificuldades de um diálogo interdisciplinar entre instituições com objetivos diferentes - a academia e o judiciário, voltados para um resultado comum - a consolidação dos vínculos na nova família. Também serão abordados o lugar a ser ocupado pelo estagiário/terapeuta e alguns impasses daí decorrentes. 


\section{SOBRE A PREPARAÇÃO DE CRIANÇAS E ADOLESCENTES NA ADOÇÃO}

O trabalho de preparação de crianças e adolescentes que se encontram institucionalizados, tendo seus genitores perdido o poder familiar, é considerado fundamental por seu potencial para prevenir ou minimizar receios e dificuldades no processo de transição e de adaptação a um novo contexto familiar. Alterações no Estatuto da Criança e do Adolescente (Lei no 8.069/1990) indicam a obrigatoriedade da preparação da criança no processo de colocação em família substituta, bem como a participação de equipe interprofissional nas tarefas a serem realizadas.

Dentre os princípios a serem adotados pelos programas de acolhimento familiar ou institucional, encontramos no Art. 92, do ECA (Lei no 8.069, de 13 de julho de 1990, com a redação dada pela Lei no 12.010 , de 2009) a tarefa de preparação gradativa para o desligamento. Mais recentemente, o Art. 197-C § 30 do ECA indica: "é recomendável que as crianças e os adolescentes acolhidos institucionalmente ou por família acolhedora sejam preparados por equipe interprofissional antes da inclusão em família adotiva" (Incluído pela Lei no 13.509, de 2017).

Ao realizarmos pesquisa bibliográfica sobre o tema em questão, verificamos a discrepância entre o grande número de produções dirigidas à preparação do adotante e o número reduzido de estudos que se dedicam à preparação e à orientação de crianças em vias de serem inseridas numa família substituta. E mais reduzido ainda quando se relaciona à interface com a universidade e seus estudantes voltados para a prática de preparação (Carvalho, Gomes, Pizzitola, Santos, \& Yshara, 2017). No contexto nacional, diversos autores (Peiter, 2011; Levy, 2014; Levy \& Gomes, 2017; Menezes \& Dias, 2018) observam a carência de publicações que relatem algum tipo de preparação gradativa para o desligamento, realizada em instituições de acolhimento, entendendo que a preparação da criança é tão imprescindível quanto a da família adotante.

Peiter já constatava, em 2011, que poucos profissionais das instituições se sentiam devidamente preparados para esta tarefa. Em seus relatos temiam levantar expectativas que não pudessem ser cumpridas. Além do mais, nos lembra como era comum que as instituições de acolhimento só recebessem a notícia do possível desligamento da criança com muito pouco tempo de antecedência, impossibilitando qualquer proposta de preparação. As informações sobre destituição do poder familiar dos pais biológicos e a indicação do candidato já habilitado Ihes vinham por meio da equipe da Vara da Infância e da Juventude, por vezes, em comunicação deficitária. Ficava nítida uma falta de integração entre as tarefas a serem executadas nas diferentes pontas de um processo que vai desde o acolhimento da criança até a sentença de sua adoção. 
Dentre as publicações mais atuais voltadas à preparação, duas investigações (Contente, Cavalcante, \& Silva, 2013; Silva, Cassarino-Perez, Sarriera, \& Frizzo, 2017) objetivaram avaliar a visão dos profissionais sobre a tarefa que Ihes cabe, a partir da redação dada pela Lei no 12.010/2009 ao ECA e encontraram resultados relativamente semelhantes. A pesquisa de Contente, Cavalcante e Silva (2013) considerou os depoimentos de técnicos do judiciário da $1^{a}$ Vara da Infância e Juventude de Belém, membros da equipe multiprofissional responsável por auxiliar e subsidiar as decisões judiciais relativas à colocação de crianças e adolescentes em família substituta. A investigação de Silva, CassarinoPerez, Sarriera e Frizzo (2017) entrevistou psicólogos e assistentes sociais judiciários de sete cidades do Rio Grande do Sul. Ambas tinham interesse em investigar como era realizado o procedimento de preparação e colocação de crianças e adolescentes e quais as propostas levantadas pelas equipes para que fossem alcançados os resultados esperados, a partir das recomendações legais.

Foi observado que os participantes da pesquisa desenvolvida por Contente, Cavalcante e Silva (2013) não se sentiam ainda capacitados para atuar na preparação de crianças segundo a determinação legal e seria necessário elaborar estratégias metodológicas adequadas para dar conta da tarefa. É reconhecido que a preparação deve ter início com uma atuação integrada das instituições de acolhimento e dos órgãos do judiciário, responsáveis pelo andamento do processo jurídico, indo desde a destituição do poder familiar até a sentença da adoção. Entretanto, enquanto alguns entrevistados nesta pesquisa comentaram que a preparação para adoção não deve ser atribuição exclusiva da equipe técnica da Justiça da Infância e da Juventude, outros informaram que, não existindo na Vara onde atuam um trabalho de preparação para a adoção, esta tarefa ficava a cargo dos profissionais dos espaços de acolhimento institucional, cuja convivência com a criança era mais constante.

No estudo desenvolvido por Silva, Cassarino-Perez, Sarriera e Frizzo (2017), foi relatado que a maioria das colocações são conduzidas pela equipe do Juizado da Infância, podendo esta contar ou não com o auxílio da equipe da instituição de acolhimento; contudo, em algumas comarcas o trabalho ainda é conduzido apenas pelas equipes dessas instituições. Nas comarcas em que havia poucos profissionais, o auxílio das equipes das instituições foi valorizado. Já onde havia um número maior de profissionais ligados ao judiciário, a equipe técnica se envolvia mais na etapa de colocação da criança, com os dados dos candidatos e com uma possível reavaliação antes do contato com a criança.

Albuquerque e Ribeiro (2018), em texto que trata da preparação dos adotantes em Recife, relatam que, diante das mudanças na legislação, as equipes técnicas das Varas de Infância e Juventude da Capital precisaram encontrar novas formas de atuação e perceberam a necessidade de focar na escuta dos desejos de crianças e adolescentes, para além da preparação dos adotantes. As equipes técnicas passaram, então, a assumir papel de apoio junto 
aos profissionais das instituições de acolhimento na tarefa de preparação, valorizando o trabalho conjunto.

Também Paiva (2014) valoriza a interdisciplinaridade e o trabalho integrado entre os técnicos das Varas e os profissionais das instituições tendo em vista que as informações compartilhadas auxiliam nos resultados alcançados. Um acompanhamento da criança pela equipe técnica das Varas faz-se necessário desde que se constata a impossibilidade de sua permanência na família de origem. Entretanto, com sua presença constante no cotidiano da criança, os profissionais da instituição de acolhimento podem verificar mais de perto as repercussões das alterações que estão ocorrendo em sua vida.

Quem são estes profissionais? Como eles se preparam para a tarefa? Os profissionais das instituições estão preparados para esta função? Peiter (2011) constata que, geralmente, não receberam apoio ou treinamento para exercê-la e externalizam suas inseguranças e inquietações. As equipes profissionais das instituições de acolhimento compostas por psicólogo, assistente social e às vezes pedagogos, nos últimos anos sofreram muitas baixas e substituições em função da precariedade das situações de trabalho encontradas, dado o pouco investimento em políticas públicas nesse setor, principalmente em comarcas pequenas.

A rotatividade de profissionais e o preenchimento das vagas por recémformados, que muitas vezes não dão conta da carga emocional associada à função, parece ser um dos empecilhos para o oferecimento de um espaço de preparação a contento. Condutas baseadas em preconceitos arraigados e valores religiosos, principalmente por parte dos cuidadores, em algumas situações pode arrefecer a possibilidade de uma nova vinculação familiar, principalmente em se tratando dos casos de devolução de crianças/adolescentes e retorno à situação de acolhimento. Portanto, em nossa experiência com alguns casos, ficou nítida a importância de uma preparação de profissionais que se dê em todos os níveis. Isso equivale a investir em maior integração entre as equipes das Varas e as das instituições de acolhimento e essas num maior acompanhamento e treinamento dos cuidadores que são os que efetivamente acompanham o dia a dia dos acolhidos.

Em relação aos principais procedimentos e etapas a serem seguidos na tarefa de preparação, encontramos na literatura referida à adoção nacional e internacional algumas sugestões. Contente, Cavalcante e Silva (2013) destacam o uso de entrevistas conjuntas com a participação da criança e dos adotantes. A tarefa de informar o adotando sobre o que está ocorrendo e as decisões que estão sendo tomadas sobre o seu futuro é fundamental no processo de transição de um ambiente que lhe é conhecido em direção a outro totalmente desconhecido, estranho. A falta de informações e de um espaço no qual tais receios venham a ser manifestados é passível de provocar resistências no decorrer deste processo. Silva, Cassarino-Perez, Sarriera e Frizzo (2017) 
observaram uma diversidade de práticas no funcionamento das comarcas investigadas, mas concluem que desde o momento em que se propõe aos pretendentes a criança a ser adotada, através de documentos, esta deveria começar a ser preparada para a apresentação à família.

Quanto às etapas sugeridas na concretização da preparação, a atividade é iniciada com a apresentação da criança disponível para adoção aos candidatos, por meio de documentos e informações que descrevam suas características. Neste momento, pretende-se definir se os candidatos têm, de fato, interesse na adoção daquela criança específica, antes que a intermediação seja feita. Em seguida, a criança deveria ser preparada para conhecer a família indicada, tarefa habitualmente realizada pelos profissionais da instituição de acolhimento ou equipes das Varas.

Tanto a pesquisa de 2017, quanto a realizada por Contente, Cavalcante e Silva (2013), valorizaram nesta etapa a apresentação da família adotiva a partir de fotos ou cartas. São dadas informações, dúvidas devem ser esclarecidas e conversas sobre as expectativas e receios diante da integração em uma nova família devem ser estimuladas. Em seguida tem-se a etapa do encontro, da apresentação entre as duas partes, dando início a um período de adaptação, que poderá ser seguido de imediato ou não do estágio de convivência, no qual se espera a construção de vínculos e um trabalho de luto pela ruptura dos laços de convivência com colegas e cuidadores da instituição de acolhimento. Os resultados das referidas pesquisas indicam a necessidade de se atentar para a ausência de consenso no que se refere à forma como a preparação de crianças e adolescentes na adoção nacional deve ser conduzida, à participação da equipe do Juizado da Infância e da Juventude no processo e ao papel dos diferentes profissionais.

Verifica-se, entretanto, que a maioria das crianças e adolescentes institucionalizados nem sempre conta com um espaço onde lhes seja possível expressar sua singularidade. A partir de uma revisão de estudos (Sólon, 2008; De Conti \& Sperb, 2009; Bento, 2010; Rossetti-Ferreira, Sólon, \& Almeida, 2010; Peiter, 2011) que salientam a relevância de uma intervenção com crianças em situação de acolhimento, Levy (2014) reafirma que a criança, enquanto sujeito com direito à voz, precisa ter a experiência de narrar a um interlocutor de modo a favorecer a construção dos significados que têm sobre o mundo e sobre si mesma.

Rosseti-Ferreira, Sólon e Almeida (2010) comentam que, ao falarem de sua história, por meio de jogos e narrativas, de interações verbais e não verbais com pessoas significativas, as crianças dela se apropriam. Assim, propõem a elaboração com a criança de um "Livro da Vida" que, a partir de fotografias, desenhos e comentários reflexivos sobre a separação da família biológica, a chegada ao abrigo e as vivências nos diferentes contextos pelos quais passou venha a ajudá-la a ressignificar sua história. Esta também é a posição de De 
Conti e Sperb (2009) quando afirmam que terão melhores condições de organizar temporalmente suas experiências ao (re)contarem a história de suas vidas na posição de Eu-narrador para um interlocutor que Ihes forneça espaço. A possibilidade de narrar a sua história de vida atua, segundo Bento (2010), como um elemento importante de mediação, facilitando a transição do contexto institucional para o contexto familiar.

Existem, assim, projetos que objetivam construir possíveis parâmetros de ação e referências visando orientar quem trabalha diariamente com crianças e adolescentes acolhidos. Alguns procedimentos e instrumentais de ação são apresentados na expectativa de que sejam úteis para profissionais de abrigos, membros dos conselhos tutelares, juízes, promotores, defensores públicos, equipes interdisciplinares das Varas da Infância e Juventude, equipes técnicas das Secretarias Municipais, além das organizações não governamentais que participam do Sistema de Garantia de Direitos e Sistema Único de Assistência Social (Bernardi, 2010).

Bernardi (2010) observa que os funcionários do serviço de acolhimento, muitas vezes, se perguntam como escutar e dar voz quando não se tem segurança sobre como lidar com o que irá escutar. Rossetti-Ferreira, Solon e Almeida (2010, p.65) se indagam sobre quem seriam os profissionais mais adequados para escutar crianças e adolescentes nas diferentes etapas que envolvem a prática de acolhimento institucional ou familiar: "a psicóloga e a assistente social do Fórum? Os técnicos do abrigo? Os educadores que estão em contato diário com a criança? A cozinheira que estabeleceu um contato especial com aquele adolescente?"; e concluem ser fundamental a parceria entre todas essas pessoas. Neste sentido, as autoras ressaltam a necessidade de investimento na qualificação dos profissionais envolvidos, que precisam estar capacitados para ouvir respeitando e compreendendo os possíveis silêncios.

Os procedimentos e ações a serem realizados pelos profissionais vinculados às CEJAIs (Comissão Estadual Judiciária de Adoção Internacional) costumam seguir um modelo proposto por Crine e Nabinger (2004), fundamentado em texto de Ombline Ozoux-Teffaine (1989). Nele, são indicadas etapas que organizam um esquema progressivo de preparação, desde um estudo sobre as especificidades do adotando, suas expectativas e receios, traumas vividos, até o acompanhamento do encontro com o(s) adotante(s), bem como durante o estágio de convivência que, para os estrangeiros, deve ter no mínimo 30 dias (Paiva, 2014).

O modelo proposto por Crine e Nabinger (2004) visava facilitar a construção de vínculo entre adotado e adotantes, iniciando-se antes mesmo de existir qualquer interessado em adotá-lo. Partia-se da premissa de que nem sempre as crianças estão prontas para vincular-se a uma nova família quando são disponibilizadas para a adoção. Assim, um trabalho de luto dá início ao processo. Nesta primeira etapa, cabe ao psicólogo estimular a criança a contar 
sua história, tanto suas lembranças da família biológica quanto as do processo de institucionalização, da mesma forma em que deve poder contar à criança fatos sobre a origem desta. O conhecimento sobre a verdade em relação a sua história é fundamental para que dela possa se apropriar e construir a memória da adoção. Como a criança geralmente tem poucas lembranças de seu passado, ela acaba por deformá-las. Neste sentido, pode-se dizer que o psicólogo se oferece como testemunha ou memória de uma história que, ao ser narrada, está sendo construída, ao mesmo tempo em que proporciona a oportunidade de elaborar as perdas sofridas e estimula o desejo de formar vínculos.

As autoras constataram que para algumas crianças o luto se mostra impossível em virtude da forte lealdade em relação à família de origem, levantando para a equipe a questão de uma possível ou não adotabilidade afetiva. Este termo é utilizado por considerar-se que, se não houver desejo por parte da criança, esta pode bloquear a formação de novos vínculos e resistir diante de uma tentativa de inseri-la em um novo núcleo familiar. O desejo e a existência de recursos psíquicos para construir laços de filiação precisariam estar presentes e verificados em uma avaliação prévia, para que os profissionais dessem início à preparação e à busca de candidatos habilitados. Para Paiva (2014), considera-se absurdo que as crianças precisem ter características específicas que as tornem suscetíveis à adoção; o que pode ocorrer é elas não estarem, no momento, devidamente preparadas, assim, não há como concordar com a fabricação de critérios de elegibilidade. Peiter (2011) relembra que as poucas pesquisas existentes sobre a preparação de crianças se referem ao processo avaliativo, que busca determinar condições de adotabilidade das crianças, ou seja, sua disponibilidade psíquica para criar novos vínculos familiares.

Focar nas representações dá continuidade ao processo de preparação. Esta etapa tem por objetivo ajudar a criança e o adolescente a representar a futura família adotiva. Para tanto, serão estimulados a expressar as representações da família que esperam ter, incluindo objetos, lugares e pessoas, independentemente de tais expectativas serem ou não realizáveis. Crine e Nabinger (2004) entendem que a formulação de expectativas indica que existe para eles um lugar psíquico para a criação de uma nova vida em família. Sugerese estimular a reflexão sobre as imagens que vão sendo construídas em relação à nova família, trabalhar o confronto da família ideal com a família real, facilitar a elaboração de experiências de separação anteriormente vividas em relação aos pais biológicos, bem como de amigos e cuidadores da instituição onde conviviam até então.

Denomina-se de Matching a etapa na qual a equipe dialoga sobre qual família responde melhor as características e expectativas da criança e vice-versa, considerando-se que algo semelhante estaria sendo feito com os adultos no país de acolhida. Busca-se dentre os candidatos habilitados aqueles que melhor 
correspondam às necessidades e expectativas da criança/adolescente. Aqui, essa preparação específica realiza-se em paralelo nos dois países, o de origem da criança e o de acolhida. A psicóloga do país de origem trabalha com a criança os dados da família escolhida para ela, auxiliada pelos profissionais da instituição. Explica-se à criança que há uma família que deseja adotá-la e esta lhe é apresentada por meio de fotos, cartas, narrativas de histórias. Procura-se trabalhar com a criança que a família que irá chegar corresponde em alguns pontos às suas expectativas, mas não corresponde em outros, introduzindo-se a noção de diferença e estrangeiro. Só então, o encontro com os adotantes é organizado e segue-se um período de convivência, que na adoção internacional tem peculiaridades, principalmente o curto período de tempo para essa fase. As atividades se encerram no país de origem, quando do momento da formalização da adoção no tribunal, diante do Juiz, momento revestido de solenidade, marcando a inscrição jurídica da nova filiação (Peiter, 2011).

Uma proposta semelhante a essa é apresentada por Corrêa e Souza (2012), na qual é ressaltada a necessidade de facilitar o percurso da realidade atual, a vivência em uma instituição de acolhimento, para a realidade futura, uma família estrangeira residente em país diverso ao de origem do adotado. Considerando-se a orientação de uma preparação gradativa para o desligamento, uma equipe interprofissional deve atestar o preparo da criança ou do adolescente para a adoção internacional. De início, consulta-se a entidade de acolhimento, identificando os profissionais indispensáveis para somar forças, como o cuidador direto da criança, o assistente social e o psicólogo do abrigo, profissionais que lidam diretamente no cotidiano da criança e são imprescindíveis ao sucesso da preparação. Destaca-se o lugar de um possível psicoterapeuta, exterior ao ambiente institucional que teria condições de estimular reflexões mais profundas e se constituiria em fonte de segurança durante o processo de preparação e o estágio de convivência. Tal profissional também teria melhores condições de avaliar o estado emocional e o desejo da criança ou do adolescente. Em seguida, organiza-se a reunião com a família estrangeira e, só então, inicia-se o estágio de convivência.

\section{O PROFISSIONAL E SUA PREPARAÇÃO}

O papel dos profissionais é destacado como elo de referência para as crianças e, por este motivo, espera-se que ele seja o mais constante possível. Sobre a preparação contínua de crianças e adotantes, Menezes e Dias (2018) utilizam os termos "suporte" e "ponte segura" quando falam do trabalho de auxiliar na travessia desde o abandono e a vida institucional até a integração à nova família. O que acaba acontecendo, contudo, são vários profissionais realizando tarefas de avaliação e acompanhamento sem que haja uma continuidade, dando margem ao temor percebido em algumas crianças de 
refazer vínculos. Quando ocorre uma devolução, constata-se a fragilidade da vinculação, levando Queiroz e Passos (2012) a incentivar o acompanhamento das famílias adotantes por equipes preparadas nesta função, na tentativa de evitar impasses no processo de formação vincular.

Além da referida função de "suporte", destaca-se o lugar do psicólogo enquanto intermediário entre a criança e as demais instâncias responsáveis pela preparação. Ozoux-Teffaine (1987) relembra que um processo de adoção implica em uma interfantasmatização entre as partes. Já para Trindade-Salavert (2010), o psicólogo, ao ocupar o lugar de intermediário, torna-se responsável por um processo de criação, transformação e passagem/transição. Assim, entende que: "esse trabalho de passagem que se tece entre adotantes e adotados não pode ser entregue nas mãos daqueles que ainda sofrem por suas próprias filiações mal construídas" (p. 29). A importância desta função encontra-se no fato de que "não se criam vínculos afetivos por encomenda" (p. 28). A partir de um mesmo ângulo, Paiva (2014) ressalta que a tarefa de preparação envolve principalmente a escuta de conteúdos subjetivos.

E quando esse profissional, na função de intermediário, é um estudante de Psicologia? É sobre essa perspectiva que relataremos uma prática interventiva, associada a um programa de estágio supervisionado, na qual a ênfase recai na preparação de crianças/adolescentes após terem sofrido uma ou mais devoluções. Por meio de vinhetas clínicas, discutiremos os alcances e limites desse tipo de intervenção e o lugar que o estagiário/terapeuta nela ocupa.

\section{DISCUTINDO A INTERVENÇÃO}

A proposta interventiva, realizada pelos estagiários, tem como meta oferecer um espaço de continência e elaboração para as vivências traumáticas, das crianças/adolescentes, relacionadas à própria história de vida e que são reatualizadas na situação de devolução. Nos casos que envolvem grupo de irmãos, há também uma solicitação das Varas para que se avalie o desmembramento ou não da fratria numa nova adoção (Gomes \& Levy, 2016). Portanto, a universidade por meio de seus serviços-escola é convocada a oferecer atendimento a uma criança/adolescente em situação de sofrimento. Veremos como a tarefa de intermediação acaba ganhando um lugar significativo durante o processo, inserindo o estagiário/terapeuta em um trabalho conjunto.

Os casos são encaminhados pelas Varas parceiras e os atendimentos ocorrem com frequência semanal, dentro do setting estabelecido pela teoria psicanalítica, nas salas disponibilizadas pela clínica-escola. Geralmente é exigido dos estagiários/terapeutas que cumpram o tripé de domínio teórico, supervisão e psicoterapia pessoal. O terapeuta deverá estabelecer contato tanto com os profissionais das equipes das Varas, psicólogo e/ou assistente social, quanto com a equipe das instituições de acolhimento. Via de regra, a convivência maior 
acaba sendo com a instituição de acolhimento (psicólogos, assistentes sociais e/ou cuidadores), pois são eles que se responsabilizam pela vinda da criança/adolescente para o atendimento.

Inicialmente há um encontro entre as equipes da Vara e da instituição de acolhimento, responsáveis pelo encaminhamento, juntamente com o estagiário designado, para uma discussão do caso. É nesse momento que o terapeuta entra em contato com os dados processuais e Ihe são comunicadas as percepções que cada profissional tem sobre a criança/adolescente que será atendida(o), desde sua acolhida. Não há uma frequência definida para essas reuniões entre as equipes; mas, a troca de informações entre os três segmentos (Vara, acolhimento e terapeuta) é constante e serve como um parâmetro decisório para o momento de se iniciar nova busca e escolha do perfil de pretendentes no Cadastro Nacional, para avaliação acerca da separação ou não de grupo de irmãos, para determinação do início do período de convivência até o estabelecimento da guarda provisória, entre outras situações que surgem ao longo do processo terapêutico.

São muitas as variáveis que influenciarão o desenrolar do processo terapêutico gerando desafios a serem encarados pela dupla aluno/terapeuta e adotado/paciente. Quanto ao estagiário, por um lado, faz-se necessária uma preparação prévia no sentido de dimensionar quais as motivações que o levaram a buscar esse tipo de experiência que o remeterá, não poucas vezes, a revisitar sua própria vivência familiar. Por outro lado, ele se vê frente a vários tipos de demandas vindas de todas as equipes de profissionais envolvidas e, sempre pressionado pelo tempo real que é muito diferente do tempo psíquico de elaboração. Esse aspecto é bastante relevante, pois exige que a intervenção tenha alguns focos - instituir novamente o desejo de família; facilitar a expressão de afetos represados e negados; valorizar a autoimagem da criança/adolescente que, na maioria das vezes, sente-se culpada pela devolução ocorrida e, retomar a esperança e credibilidade na capacidade de se vincular. Para isso, o trabalho terapêutico contará com a capacidade empática e humana do estagiário, no contato com a criança ou adolescente, acrescido da utilização de instrumentos facilitadores como a caixa lúdica, jogos e, na atualidade, o celular.

Uma primeira situação a ser relatada e analisada traz a necessidade do estagiário se posicionar como interlocutor de duas equipes - a da Vara e a da Instituição - em nome do que emerge no discurso da criança/adolescente. Neste sentido seu lugar de intermediário. João ${ }^{1}, 12$ anos, mais velho de três irmãos, após duas experiências negativas, uma de convivência com um casal heterossexual e outra com um homem solteiro, chega à terapia fechado, cabisbaixo. A conversa inicial foi estabelecida via papel e lápis. Após algumas

\footnotetext{
${ }^{1}$ Todos os nomes são fictícios.
} 
sessões, quando se coloca um pouco mais aberto, João pergunta se eles podem assistir alguns vídeos no celular do terapeuta. Aqui se cria um verdadeiro canal de trocas e identificações, pois através dos personagens dos vídeos elencados, 0 terapeuta vai adentrando as angústias de João.

Passados alguns meses, João é surpreendido com a possibilidade de ser adotado pela mãe de seu irmão do meio, a quem já conhecia por participar das festas em família, principalmente Natal e aniversário do irmão. Entretanto, para surpresa de todos, João assume forte atitude de recusa. Foi necessário ao terapeuta colocar-se firmemente no lugar de intermediação entre a equipe do Fórum e da instituição de acolhimento, pois a primeira queria rapidamente implementar os procedimentos para a adoção já que a pretendente era conhecida e temiam que ela desistisse do intento. Nesse caso, a possibilidade de um diálogo próximo e constante entre essas três instâncias, terapeuta e as duas equipes, permitiu estender o tempo de reflexão com João e com a pretendente, para que ela pudesse aguardar um pouco mais a decisão dele, com o consentimento da equipe da Vara.

A cena a seguir levanta a importância de um trabalho com a contratransferência de quem prepara. Maria, uma garotinha de três anos, desde seu nascimento na instituição, vem para ser atendida após duas tentativas frustradas de colocação em família substituta. É só nesse espaço que os profissionais envolvidos conseguem entender por que Maria não havia conseguido cativar os pretendentes anteriores, já que ela estava dentro do perfil escolhido. Numa publicação anterior (Gomes, Marques, \& Yshara, 2017) demonstramos como os sentimentos contratransferenciais despertados na terapeuta e discutidos em supervisão foram um instrumento importante para a compreensão das reais necessidades da menina a partir do entendimento da sua dinâmica de funcionamento interno. A inquietude, angústia e frustração vivenciadas pela terapeuta eram geradas diante da impossibilidade de Maria permitir ser cuidada.

Essa experiência terapêutica foi um marco para o restabelecimento da capacidade de se vincular da menina, incluindo todos os riscos inerentes ao encontro com o outro. Como resultado concreto do atendimento, observaram-se ainda progressos em seu desenvolvimento, principalmente no que dizia respeito à fala e à capacidade simbólica. Por meio desses sentimentos transferenciais e contratransferenciais pudemos, junto com os técnicos da Vara, avaliar quais características essenciais deveriam ser levadas em conta para uma nova busca no cadastro de pretendentes. Era necessário um casal que pudesse conter e respeitar o ritmo de se vincular da criança e, fundamentalmente, que respeitasse sua alteridade.

Na delicada posição de intermediário, o estagiário/terapeuta estará ao lado da criança, escutando seu discurso e procurando filtrar o que the é dito ou solicitado também pelos outros atores envolvidos. Ele se defrontará com as 
convicções dos cuidadores e da equipe técnica acerca do que seria o melhor para a criança e muitas vezes com situações que envolvem uma tendência a culpabilizar a criança ou até mesmo a si, como nos dois relatos seguintes.

Daniel, sete anos, vem por indicação da Vara para que se reitere a opinião do juiz de separá-lo dos irmãos menores. Com apenas três atendimentos realizados, a assistente social cobra uma decisão, pois o mesmo juiz quer que se inicie a busca no Cadastro Nacional de Adotantes (CNA). No último atendimento, o menino é trazido por uma cuidadora da instituição de acolhimento que pede para a terapeuta conversar com Daniel, pois este fica sempre muito distante dos outros dois irmãos e ela acredita que ele não pode agir assim: "ter irmão é uma dádiva de Deus! Ele como mais velho precisa cuidar deles, ficar no lugar dos pais". A criança se vê diante de um discurso que a culpabiliza pela possibilidade de vir a ser adotada sozinha.

Muitas vezes, como na vinheta acima, o terapeuta se vê em meio a demandas e condutas tão desencontradas que, para ele próprio não ser levado por algum tipo de atuação, é sempre necessário retomar o lugar e a função de psicólogo frente à criança, distanciando-se dos desejos expressos pelas demais instâncias decisórias.

Num outro episódio, sobre a escolha de pretendentes para um menino de seis anos, já tendo vivido uma devolução, fica nítida a tentativa de se encontrar um culpado pelos fracassos e, novamente, a importância do entrosamento entre as equipes. Após o estagiário ter entrevistado dois casais de pretendentes habilitados, indicados pela psicóloga da Vara, e Ihes apresentado as necessidades da criança e seus recursos, ambos desistiram de conhecer o garoto. Frente a isso, em reunião com o estagiário e os profissionais do acolhimento, a psicóloga repreende o terapeuta dizendo que por exigência dele, provavelmente, o menino cresceria sem uma família.

Esse fato nos leva a refletir sobre o que se espera da preparação dos adotantes. Adoção a qualquer preço? Preparar os futuros pais também significa levá-los a entender as dificuldades que podem advir do encontro com a criança. A desistência neste momento de apresentação adquire um caráter preventivo, pois antecipa o que poderia ser uma devolução, caso a preparação dos adotantes não os faça entrar em contato com seus limites emocionais reais, para além da idealização de conseguirem o filho que sempre quiseram.

As crianças que vão se distanciando do perfil escolhido pelos pretendentes mobilizam todos a sua volta. Começando pelos estagiários/terapeutas, a pouca experiência clínica é suplementada por uma genuína disponibilidade afetiva. Não é raro que, ao longo dos atendimentos, algumas crianças comecem a desejar que o terapeuta se torne o pai ou a mãe e se interessem em saber como é a família desses. Desejo que desperta principalmente naquelas que se mostravam resistentes, em clara atitude defensiva. Verifica-se, a partir do vínculo transferencial, o início de uma retomada da capacidade de vinculação. Essa 
constatação vai ao encontro do pensamento de Corrêa e Souza (2012) que mencionam como um psicoterapeuta, exterior ao ambiente institucional, poderia, ao facilitar projeções, permitir uma maior compreensão sobre o estado emocional e o desejo da criança ou do adolescente.

Outro aspecto a ser considerado relaciona-se ao fato da maioria dos estagiários estarem ainda na condição de filhos. Assim, é frequente uma atitude de maior identificação com a criança/adolescente, que não pôde ser cuidada (seja pela família biológica ou adotiva), e um posicionamento de antemão crítico aos adultos que se sentem impossibilitados de exercer esse cuidado. Já havíamos mencionado a preocupação percebida por Bernardi (2010), entre os profissionais que se perguntavam como escutar e dar voz à criança quando não se tem segurança sobre a forma de lidar com o que irão escutar. É dentro dessa perspectiva que a discussão do caso na supervisão, geralmente em grupo e após cada atendimento realizado pelo estagiário, permite um maior distanciamento entre as experiências pessoais e a compreensão do outro, no sentido de o terapeuta buscar a necessária abstinência no exercício de sua função.

Nos casos atendidos em colaboração com a Vara, a finalização do processo terapêutico se dá quando tem-se a adequada inserção da criança/adolescente na nova família, salvo algumas exceções nas quais os adotantes concordam em dar prosseguimento ao atendimento do adotado. No pós-adoção, por vezes, são solicitadas orientações em função de dificuldades específicas da criança/adolescente e dos próprios adotantes, no exercício das funções parentais.

Os atendimentos, via de regra, têm a duração de alguns meses. No geral, busca-se adaptar o tempo de elaboração psíquica às exigências do tempo real, ou seja, nas adoções tardias, e principalmente no caso dos adolescentes, há uma urgência na preparação dos adotantes, pois se corre o risco de não se encontrar pretendentes para esses perfis, ficando apenas a adoção internacional como possibilidade remota.

$\mathrm{Na}$ maioria dos encerramentos, sugere-se, de acordo com a literatura científica vigente, que a dupla terapeuta/adotado construa algo que simbolize o momento vivido de finalização de um vínculo e início de um novo. São utilizadas algumas estratégias facilitadoras para a elaboração desse momento de separação, envolvendo uma construção criada pela dupla, como desenhos, recortes, colagens, conteúdos escritos, que representam a história daquela experiência. Embora permeado de sentimentos ambivalentes, para ambos, objetiva-se a elaboração de uma situação emocional que, com certeza, faz parte do viver e é de natureza muito diferente das interrupções ou abandonos vinculares. 


\section{CONSIDERAÇÕES FINAIS}

As recomendações propostas pela legislação em 2009 e em 2017 impulsionaram a necessidade de desenvolver procedimentos para a realização da preparação de crianças e adolescentes, visando o desligamento institucional e a entrada em nova família. As equipes técnicas das diversas comarcas brasileiras vêm tentando construir sua própria metodologia. Muitas encontram problemas similares, como o reduzido número de profissionais para a execução da tarefa. Procura-se, então, juntar forças com as equipes das instituições de acolhimento, mas nem sempre estes profissionais estão capacitados e precisam também ser preparados. Outra solução encontrada é a de contar com parcerias, principalmente aquelas provenientes das universidades, como apresentado neste artigo.

Enfatizamos as nuances de um trabalho entre equipes e a importância da prática interventiva de preparação com adotantes e adotados na formação clínica do estagiário em Psicologia. Sob essa perspectiva, amplia-se o escopo da preparação para preparar quem prepara, ou seja, a preparação do estagiário, a do cuidador e a dos psicólogos das instituições e da Vara, havendo aqui uma percepção generalizada acerca de uma deficiência nesse campo.

No caso específico dos estagiários, em seu lugar de terapeutas, precisam ainda lidar com a tarefa de intermediação, distanciando-se das pressões inerentes aos outros profissionais que, na maior parte das vezes, pretendem acelerar o processo. É necessário um cuidado diante da expectativa de "resolver o problema" e, com isto, perder a capacidade de escuta. Para o estudante, a presença do supervisor cria um espaço de apoio, da mesma forma que nas pesquisas aqui mencionadas valoriza-se o papel de apoio das equipes técnicas junto aos profissionais das instituições de acolhimento. Destacamos a necessidade de um olhar específico aos cuidadores, pois são eles que permanecem mais tempo com as crianças/adolescentes e são os primeiros a viverem a separação vincular quando ocorre encaminhamento para a família substituta.

Quanto às vinhetas analisadas, elas confirmam o espaço privilegiado de escuta do estagiário/terapeuta para com as narrativas das crianças e/ou adolescentes e o consequente processo elaborativo que surge tornando-as aptas para nova possibilidade vincular. Se por um lado fica evidente a importância do entrosamento entre as equipes, por outro deve-se atentar para as diferentes funções que cada profissional exerce, seja no trato com os pretendentes ou com as crianças e/ou adolescentes. Em decorrência disso, encontramos demandas que se apresentam até certo ponto antagônicas e, se não forem percebidas a tempo, podem interferir negativamente na melhor condução do caso, como apresentado particularmente nos relatos 3 e 4 . 
Embora tenhamos priorizado nas vinhetas a preparação de crianças/adolescentes que já haviam vivido uma devolução, o que envolve uma maior complexidade no processo de construção de novos vínculos, fica nítido que, qualquer que seja o caso, a colocação em família substituta será facilitada quanto maior for a integração no trabalho em equipe. Concluindo, não restam dúvidas de que, sob o vértice da formação clínica do graduando de Psicologia, essa experiência é uma oportunidade rica para o desenvolvimento pessoal e profissional, bem como de pesquisa e geração de conhecimento na interface interdisciplinar.

\section{DECLARAÇÃO DE CONFLITOS DE INTERESSE}

Não há conflitos de interesse.

\section{REFERÊNCIAS}

Aguirre, A. M. B., Herzberg, E., Pinto, E. B., Becker, E., Carmo, H. M. S., \& Santiago, M. D. E. (2000). A formação da atitude clínica no estagiário de psicologia. Psicologia USP, 11(1), 49-62. https://dx.doi.org/10.1590/S0103-65642000000100004.

Albuquerque, C. M. M., \& Ribeiro, P.M. (2018). A adoção e a preparação para a filiação adotiva em Recife: o olhar da psicologia. In C. M. S. B. Dias, L. V. C. Moreira, (Orgs.). Adoção, família e institucionalização; interfaces psicossociais e jurídicas, (pp. 63-79). Curitiba: Editora CRV.

Bento, R. (2010). A história de vida de crianças e adolescentes como mediadora da reintegração no contexto familiar. (Dissertação de Mestrado). Pontifícia Universidade Católica de São Paulo, São Paulo.

Bernardi, D. C. F. (2010). A voz das crianças em situação de acolhimento. In: Bernardi, D. C. F. (Org.). Cada caso é um caso: a voz das crianças e dos adolescentes em acolhimento institucional (pp. 49-60). São Paulo: Associação Fazendo História. Disponível em: https://www.neca.org.br/wpcontent/uploads/Livro5.pdf.

Carvalho, F. A., Gomes, I. C., Pizzitola, J. M.; Santos, M., \& Yshara, Y. (2017). Grupos reflexivos com pretendentes a adoção: alcances e limites. In M.Y. Okamoto, T. S. Emídio (Orgs.). Perspectivas psicanalíticas atuais para o trabalho com grupos e famílias na Universidade (pp. 48-67). 1 ed. São Paulo: Cultura Acadêmica.

Contente, S. R., Cavalcanti, L. I. C., \& Silva, S. S. C. (2013). Adoção e preparação infantil na percepção dos profissionais do juizado da infância e juventude de Belém/PA. Temas em Psicologia, 21(2), 317-333. https://dx.doi.org/10.9788/TP2013.2-02 
Corrêa, T. B., \& Souza, J. S. (2012). Metodologia de Intervenção no Processo de Preparação para a Adoção Internacional - a prática da Comissão Distrital Judiciária de Adoção - CDJA. Brasília. TJDFT. Disponível em http://www.tjdft.jus.br.

Crine, A. M., \& Nebinger, S. (2004). La mise en relation de l'enfant et de ses futurs parents dans l'adoption internationale. In O. Ozoux-Teffaine (org.), Enjeux de l'adoption tardive - Nouveaux fondements pour la clinique (pp. 169-188). Ramonville Saint-Agne: Editions Ères.

De Conti, L., \& Sperb, T. M. (2009). A composição de narrativas pela dupla terapeuta-paciente: uma análise da sua organização e da sua sequência de ações. Psicologia: Reflexão e Crítica, 22(1), 119-127. https://dx.doi.org/10.1590/S0102-79722009000100016

De Fillippo, T. M. (2008). Como alguém pode tornar-se psicanalista? Fractal: Revista de Psicologia, 20(2), 409-420. https://dx.doi.org/10.1590/S1984$\underline{02922008000200008}$

Freud, S. (1912/1980). Recomendações aos médicos que exercem a Psicanálise. In Edição Standard Brasileira das Obras Completas de Sigmund Freud (ESB), Vol. XII. Rio de Janeiro: Imago.

Gomes, I. C. (2005). A formação clínica do estagiário de psicologia em atendimento a casais e famílias na abordagem psicanalítica. In T. FéresCarneiro (Org.), Família e Casal: efeitos da contemporaneidade (pp. 304316). Rio de Janeiro: Editora PUC/RJ.

Gomes, I. C., \& Levy, L. (2016). A psicanálise vincular e a preparação de crianças para a adoção: uma proposta terapêutica e interdisciplinar. Contextos Clínicos, 9(1), 109-117. https://dx.doi.org/10.4013/ctc.2016.91.09

Gomes, I. C., Marques, R. T. \& Yshara, Y. (2018). Encontros e desencontros na adoção: o paradoxo da ilusão. In G. K. Levinzon, A. D. Lisondo (Orgs.). Adoção: Desafios da contemporaneidade (pp.221-234). São Paulo: Edgard Blücher Ltda.

Lei no 8.069, de 13 de julho de 1990. (1990, 16 jul.). Dispõe sobre o Estatuto da Criança e do Adolescente e dá outras providências. Diário Oficial da União. Recuperado em http://www.planalto.gov.br/ccivil 03/leis/l8069.htm

Lei no 12.010/2009, de 3 de agosto de 2009. (2009, 04 ago.). Dispõe sobre adoção; altera as Leis nos 8.069, de 13 de julho de 1990 - Estatuto da Criança e do Adolescente, 8.560, de 29 de dezembro de 1992; revoga dispositivos da Lei no 10.406, de 10 de janeiro de 2002 - Código Civil, e da Consolidação das Leis do Trabalho - CLT, aprovada pelo Decreto-Lei no 5.452, de $1^{0}$ de maio de 1943; e dá outras providências. Diário Oficial da União. Recuperado em http://www.planalto.gov.br/ccivil 03/ ato20072010/2009/ lei/l12010.htm 
Levy, L., \& Gomes, I. C. (2017). Grupos de preparação à adoção: dos pretendentes às crianças. In T. Féres-Carneiro (Org.), Casal e família: teoria, pesquisa e clínica (pp.157-174). Rio de Janeiro: Editora PUC/RJ.

Levy, L. (2014). Construindo Histórias. In C. Ladvocat (Org.), Guia da adoção: No jurídico, no social, no psicológico e na família (pp.353-360). São Paulo, SP: Roca.

Marcos, C. M. (2011). Reflexões sobre a clínica-escola, a psicanálise e sua transmissão. Psicologia Clínica, 23(2), 205-220. https://dx.doi.org/10.1590/S0103-56652011000200013

Meira, C. H. M. G., \& Nunes, M. L. T. (2005). Psicologia clínica, psicoterapia e o estudante de psicologia. Paidéia (Ribeirão Preto), 15(32), 339-343. https://dx.doi.org/10.1590/S0103-863X2005000300003

Menezes, K. F. L., \& Dias, M. C. de S. B. (2018). Adoção: a construção de uma nova família. In C. M. S. B. Dias, L. V. C. Moreira, (Orgs.), Adoção, família e institucionalização; interfaces psicossociais e jurídicas, (pp. 21-39). Curitiba: Editora CRV.

Ozoux-Teffaine, O. (1987). Adoption tardive - D'une naissance à l'autre. Paris, Éditons Stock.

Paiva, L. D. (2014). Escuta e preparação da Criança para construção de uma nova família na Adoção internacional. In C. Ladvocat (Org.), Guia da adoção: No jurídico, no social, no psicológico e na família (pp. 331-341). São Paulo: Roca.

Peiter, C. (2011). Adoção - Vínculos e rupturas: Do abrigo à família adotiva. São Paulo: Zagodoni Editora.

Queiroz, E., \& Passos, M. C. (2012) Apresentação. In E. Queiroz, M. C. Passos (Orgs.). A clínica da adoção (pp. 17-21). Recife: Editora Universitária da UFPE.

Rossetti-Ferreira, M. C., Sólon, L. A. G., \& Almeida, I. G. (2010). A delicada arte da conversa e da escuta. In D. C. F. Bernardi (Org.), Cada caso é um caso: a voz das crianças e dos adolescentes em acolhimento institucional (pp.6173). São Paulo: Associação Fazendo História. Disponível em: https://www.neca.org.br/wp-content/uploads/Livro5.pdf.

Sandler, J., Dare, C., \& Holder, A. (1977). O paciente e o analista: fundamentos do processo psicanalítico. Rio de Janeiro: Imago.

Sei, M. B., \& Gomes, I. C. (2017). Caracterização da clientela que busca a psicoterapia psicanalítica de casais e famílias. Psicologia: teoria e prática, 19(3), 70-83. https://dx.doi.org/10.5935/1980-6906/psicologia.v19n3p7083

Silva, P. S., Cassarino-Perez, L., Sarriera, J. C., \& Frizzo, G. B. (2017). A Equipe Psicossocial na Colocação da Criança nos Processos de Adoção. Psicologia: Ciência e Profissão, 37(3), 608-623. https://dx.doi.org/10.1590/19823703000382016 
Sólon, L. A. G. (2008). Conversando com crianças sobre adoção. São Paulo, SP: Casa do Psicólogo.

Trindade-Salavert, I. (2010) Subjetividades que se interligam. In I. TrindadeSalavert (Org.), Os novos desafios da adoção - interações psíquicas, familiares e sociais (pp.15-43). Rio de Janeiro: Companhia de Freud.

Zanetti, S. A. S., \& Gomes, I. C. (2016). Grupo terapêutico de mediação e a formação clínica em casais e famílias. Psicologia Clínica, 28(3), 53-72. Recuperado em 27 de maio de 2019, de http://pepsic.bvsalud.org/scielo.php?script=sci arttext\&pid=S0103-

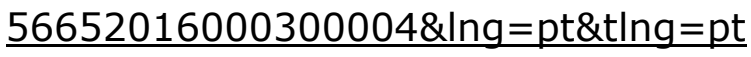

Zuanazzi, A. C. (2015). Terapia psicanalítica familiar: um estudo investigativo sobre o processo terapêutico de casos atendidos por estudantes de psicologia em um serviço-escola (Dissertação de Mestrado). Universidade de São Paulo, São Paulo.

Zuanazzi, A. C., \& Gomes, I. C. (2018). Atendimento psicanalítico a famílias e casais nos serviços-escola: a importância da supervisão na formação do aluno/estagiário. In M. L. T. Moretto, D. Kupermann (Orgs). Supervisão: $A$ formação clínica na Psicologia e na Psicanálise (pp. 55-68). São Paulo: Zagodoni Editora Ltda e Fapesp.

Sobre os autores

Isabel Cristina Gomes, Psicóloga, Psicanalista, Mestre e Doutora pelo IPUSP, Livre-docente e Professora Titular do Departamento de Psicologia Clínica do IPUSP. Área de atuação: Adoção e Psicanálise de Casal e de Família.

isagomes@usp.br

Lidia Levy, Psicóloga, Psicanalista, Mestre e Doutora em Psicologia Clínica pela PUC-Rio. Coordenadora do Curso de Especialização em Psicologia Jurídica da PUC-Rio. Área de atuação: Psicologia Jurídica e Psicanálise de Casal e de Família. llevy@puc-rio.br

A contribuição de cada autor pode ser atribuída como se segue: Isabel Cristina Gomes e Lídia Levy contribuíram igualmente para a conceitualização, relato e análise do material, preparação do artigo, revisão da escrita e formatação do original.

Recebido em: 04/06/2019

Revisado em: 12/07/2019

Aceito em: $19 / 12 / 2019$ 